\title{
PENERAPAN E-COMMERCE DENGAN CONTENT MANAGEMENT SYSTEM WORDPRESS PADA TOKO FIKHRI FAHRUL COLLECTION
}

\author{
Muhammad Hanafi Nasution ${ }^{1)}$, Yudi Santoso ${ }^{2)}$ \\ ${ }^{1}$ Sistem Informasi, Fakultas Teknologi Informasi, Universitas Budi Luhur \\ ${ }^{1,2} \mathrm{Jl}$. Raya Ciledug, Petukangan Utara, Kebayoran Lama, Jakarta Selatan 12260 \\ E-mail : $\underline{\text { mhanafi847@gmail.com }}^{1)}$, yudi.santoso@budiluhur.ac.id ${ }^{2)}$
}

\begin{abstract}
Abstrak
Toko Fikhri Fahrul Collection merupakan salah satu usaha yang bergerak dalam bidang penjualan celana jogger, penjual mengeluhkan sedikitnya pelanggan pada penjualan produknya sehingga pendapatan yang masuk hanya sedikit dan diluar dari ekspetasi yang diinginkan. Penjual mengharapkan agar tokonya mendapatkan pendapatan maksimal. Toko Fikhri Fahrul Collection juga masih menggunakan proses transaksi manual sehingga proses transaksi nya hanya dapat diakses di satu tempat. Maka dari itu, penulis mencoba untuk menerapkan E-Commerce menggunakan Content Management System WordPress pada Toko Fikhri Fahrul Collection dengan memanfaatkan teknologi internet sehingga proses penjualannya dapat diakses kapan saja dan dimana saja menggunakan internet. Supaya penjual bisa untuk memasarkan produk-produknya secara luas (tidak terpaku dalam satu tempat saja) dan meraih keuntungan yang lebih besar dari sebelumnya yang pendapatannya kurang maksimal dari yang diinginkan penjual karena hanya menjual produknya di satu tempat saja.
\end{abstract}

Kata kunci: E-Commerce, Business Model Canvas, Content Management System, WordPress.

\section{PENDAHULUAN}

\subsection{Latar Belakang}

E-Commerce atau biasa disebut dengan perdagangan elektronik adalah suatu kegiatan penjualan seperti kegiatan penjualan pada umumnya, yang membedakan adalah para pihak yang bertransaksi tidak bertemu tatap muka secara langsung tetapi melalui media internet[1]. Dengan hadirnya E-Commerce ini membuat banyak keuntungan dari berbagai pihak, baik dari pihak pelanggan maupun pihak penjual. Tentunya dengan adanya konsep E-Commerce ini lebih mudah untuk melakukan bertransaksi dibandingkan dengan konsep belanja pada umumnya. Selain proses transaksi bisa menjadi lebih mudah, konsep ECommerce dapat meminimalisir banyak biaya operasional karena penjual tidak harus mempunyai toko fisik.

Toko Fikhri Fahrul Collection merupakan salah satu usaha yang bergerak dalam bidang penjualan celana jogger, penjual mengeluhkan sedikitnya pelanggan pada penjualan produknya sehingga pendapatan yang masuk hanya sedikit dan diluar dari ekspetasi yang diinginkan. Penjual mengharapkan agar tokonya mendapatkan pendapatan maksimal.

Maka dari itu, penulis mencoba untuk menerapkan E-Commerce pada Toko Fikhri Fahrul Collection dengan memanfaatkan teknologi internet menggunakan Content Management System Wordpress sehingga proses penjualannya dapat diakses kapan saja dan dimana saja menggunakan internet. Content Management System adalah aplikasi berbasis website yang digunakan untuk memposting suatu artikel, meng-edit halaman website, mengatur tampilan menu dan mengatur tampilan website[2]. Sedangkan Wordpress adalah salah satu jenis Content Management System yang paling banyak digunakan, seseorang tidak harus mahir dalam programming untuk membuat sebuah website. Hanya dengan beberapa sentuhan, seseorang bisa membuat website dengan mudah menggunakan Content Management Sytem Wordpress ini[3].

\subsection{Masalah}

Berdasarkan latar belakang yang sudah dijelaskan, maka penulis merangkum masalah yang ada pada Toko Fikhri Fahrul Collection sebagai berikut:

a. Untuk melihat dan membeli produk yang diinginkan, pelanggan harus mendatangi ke toko tersebut untuk melihat dan membeli produknya.

b. Sedikitnya informasi ter-update mengenai produk baru bagi pelanggan.

c. Tidak adanya laporan mengenai produk terlaris, pengiriman, penjualan, pengembalian dana, retur, potongan harga, rekapitulasi.

\section{METODE PENELITIAN}

Kerangka pemikiran merupakan langkah yang dilakukan penulis dalam menjalankan penelitian yang akan dilakukan. Berikut adalah kerangka pemikiran yang dibuat dalam karya ilmiah ini: 


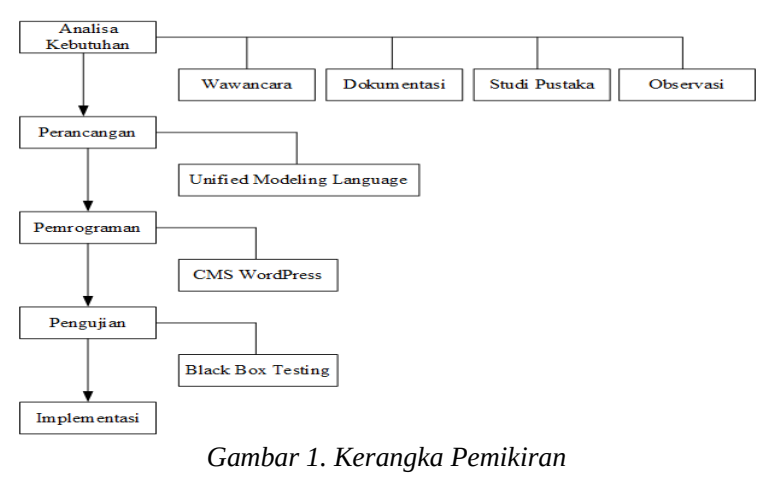

Berikut adalah penjelasan kerangka pemikiran yang penulis buat di dalam karya ilmiah ini:

a. Analisa Kebutuhan

Penulis memakai teknik wawancara, dokumentasi, studi pustaka dan observasi untuk mengumpulkan data-data yang diperlukan untuk penelitian.

b. Perancangan

Pada tahapan ini penulis merancang sistem yang akan dibuat menggunakan UML (Unified Modeling Language).

c. Pemrograman

Di dalam membuat program ini, penulis menggunakan CMS (Content Management system) dengan WordPress untuk membangun program.

d. Pengujian

Setelah sistem dibuat, langkah selanjutnya yang penulis lakukan adalah melakukan pengujian. Teknik yang digunakan adalah dengan Black Box Testing, yaitu dengan menguji fungsi dari sistem dan melihat hasil yang dihasilkan oleh sistem.

e. Penerapan

Setelah sistem sudah di uji pada tahap pengujian untuk memastikan sistem berjalan dengan baik, berikutnya adalah menerapkan sistem yang sudah di uji tersebut kepada toko Fikhri Fahrul Collection.

\section{HASIL DAN PEMBAHASAN}

\subsection{Business Model Canvas (BMC)}

Business Model Canvas adalah kerangka kerja untuk memetakan bisnis kita agar kinerja kedepannya menjadi lebih baik.[4]. Berikut adalah Business Model Canvas yang penulis buat di dalam karya ilmiah ini:

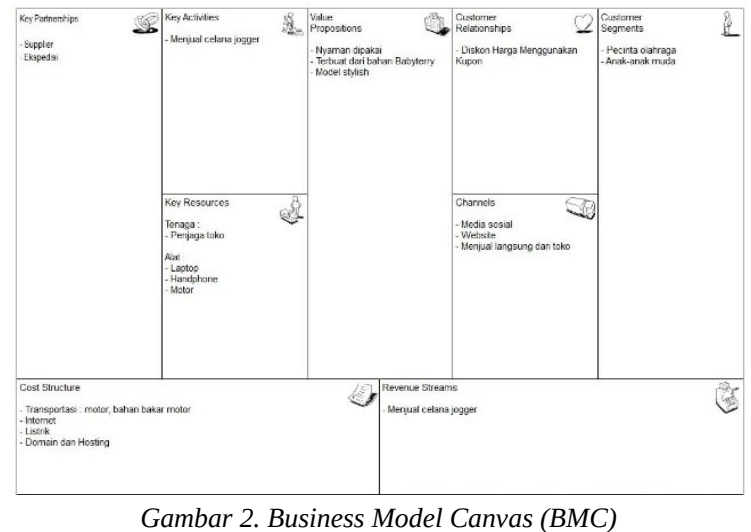

Berikut adalah penjelasan elemen-elemen yang terdapat di dalam Business Model Canvas, yaitu:

a. Key Partners

Berisi tentang beberapa mitra yang berkerja sama dengan Toko Fikhri Fahrul Collection untuk menjalankan sebuah bisnisnya. Berikut Key Partners pada penelitian ini, yaitu:

- Supplier

- Ekspedisi

b. Key Activities

Kegiatan apa saja yang dilakukan dalam sebuah bisnis untuk menentukan keberhasilan pada bisnisnya. Kegiatan yang dilakukan pada Toko Fikhri Fahrul Collection, yaitu:

- Menjual celana jogger

c. Key Resources

Sumber daya yang dibutuhkan untuk menentukan keberhasilan pengoperasian model bisnis pada Toko Fikhri Fahrul Collection, yaitu:

- Penjaga Toko

- Laptop

- Handphone

- Motor

d. Value Proposition

Nilai lebih pada produk yang membuat pelanggan agar lebih memilih produk pada Toko Fikhri Fahrul Collection, yaitu:

- Nyaman dipakai

- Terbuat dari bahan Babyterry

- Model Stylish

e. Customer Relationship

Berisi tentang hubungan kepada pelanggan untuk mendapatkan pelanggan baru atau mempertahankan pelanggan yang sudah ada pada Toko Fikhri Fahrul Collection, yaitu:

- Diskon harga menggunakan kupon

f. Channels

Saluran yang digunakan oleh Toko Fikhri Fahrul Collection untuk berkomunikasi dengan para pelanggannya, yaitu:

- Media Sosial

- Website 
- Menjual langsung dari toko

g. Customer Segments

Target pelanggan dalam bisnis pada Toko Fikhri Fahrul Collection, yaitu:

- Pecinta olahraga

- Anak-anak muda

h. Cost Structure

Biaya struktur yang dikeluarkan setelah dioperasikannya bisnis pada Toko Fikhri Fahrul Collection, yaitu:

- Motor

- Bahan Bakar Motor

- Internet

- Listrik

- Domain dan Hosting

i. Revenue Streams

Pendapatan atau pemasukan yang didapat dari bisnis pada Toko Fikhri Fahrul Collection, yaitu:

- Menjual celana jogger

\subsection{Activity Diagram}

Activity diagram adalah diagram yang digunakan untuk menggambarkan alur suatu aktifitas[5]. Berikut adalah activity diagram yang dibuat penulis dalam karya ilmiah ini:

a. Activity Diagram Pemesanan

Pelanggan harus login terlebih dahulu, dan pelanggan memilih menu Belanja/Kategori. Selajutnya memilih produk yang diinginkan. Lalu memilih ukuran dan jumlah produknya, selanjutnya klik add to cart, lalu klik view cart. Setelah itu klik proceed to checkout dan mengisi data checkout. Selanjutnya klik place order, maka pesanan berhasil dibuat.

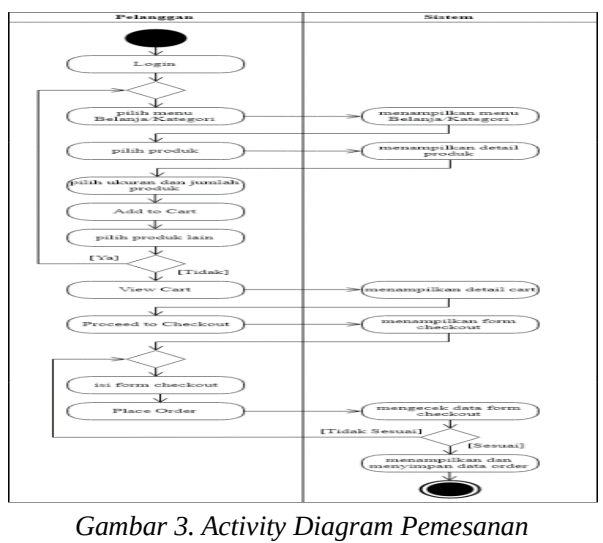

b. Activity Diagram Konfirmasi Pembayaran

Pelanggan melakukan konfirmasi pembayaran dengan cara memilih menu Akun Saya dan pilih Confirm Payment dan mengisi data pada form konfirmasi pembayaran yang disediakan. Sistem akan mengirim data tersebut ke Admin untuk dilakukan pengecekan apakah sesuai atau tidak.

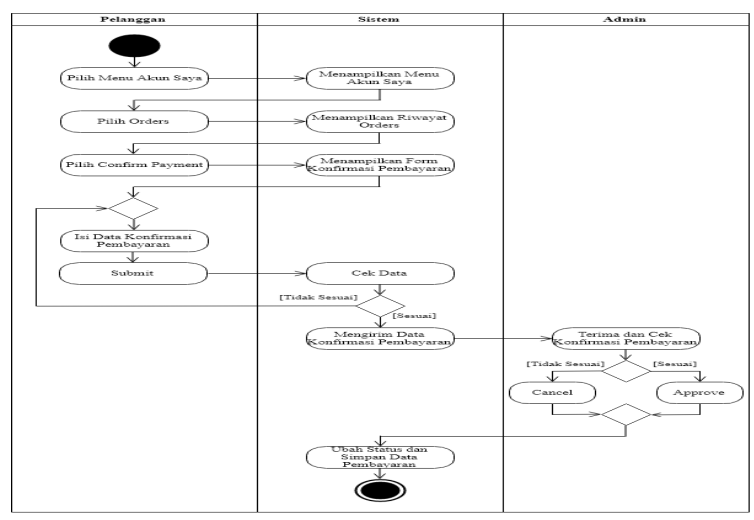

Gambar 4. Activity Diagram Konfirmasi Pembayaran

c. Activity Diagram Cetak Laporan

Admin login ke dashboard wp-admin terlebih dahulu untuk mencetak laporan potongan harga, laporan pengiriman, laporan penjualan, laporan pengembalian dana, laporan rekapitulasi, laporan retur, laporan produk terlaris.

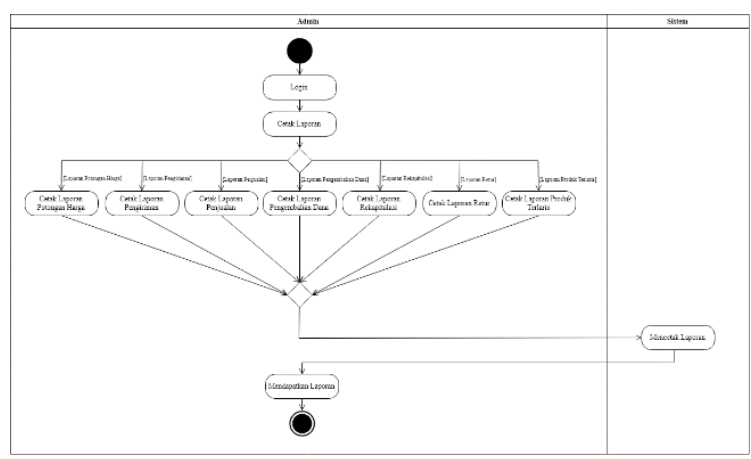

Gambar 5. Activity Diagram Cetak Laporan

\subsection{Use Case Diagram}

Use case diagram adalah diagram yang digunakan untuk menggambarkan hubungan suatu sistem dengan aktor yang melaksanakannya[6]. Berikut adalah use case diagram yang dibuat oleh penulis dalam karya ilmiah:

a. Use Case Diagram Transaksi

Pada use case diagram transaksi, terdapat dua aktor pelanggan dan admin. Pelanggan melaksanakan pemesanan pada produk, konfirmasi pembayaran produk yang sudah dipesan, retur barang dan refund barang. Sedangkan pada aktor admin melaksanakan memantau pesanan pelanggan, verifikasi pembayaran dan entry nomor resi. 


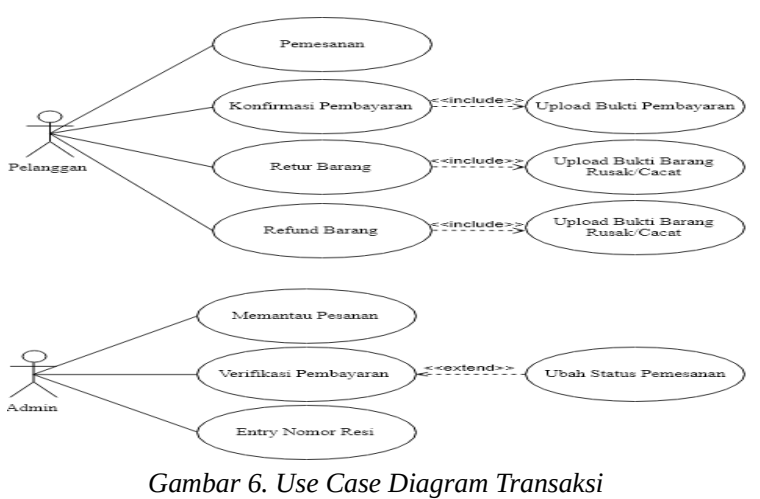

b. Use Case Diagram Laporan

Pada use case diagram laporan, terdapat aktor admin yang melaksanakan mencetak laporanlaporan yang terdiri dari: laporan produk terlaris, laporan pengiriman, laporan penjualan, laporan pengembalian dana, laporan retur, laporan potongan harga, laporan rekapitulasi.

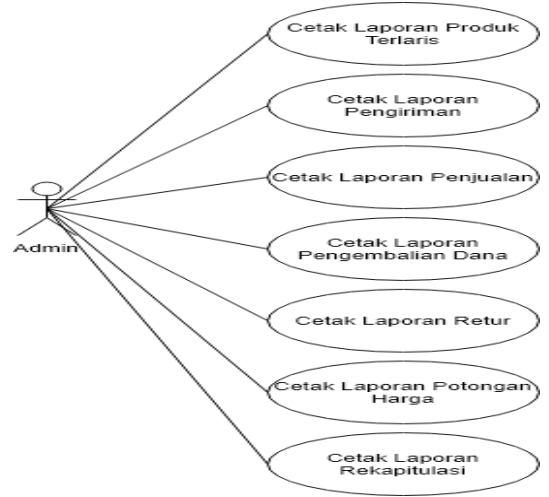

Gambar 7. Use Case Diagram Laporan

\subsection{Class Diagram}

Class Diagram adalah diagram yang digunakan untuk pengembangan berorientasi object atau Object Oriented Programming (OOP)[7]. Berikut adalah gambar class diagram yang dibuat oleh penulis dalam karya ilmiah ini:

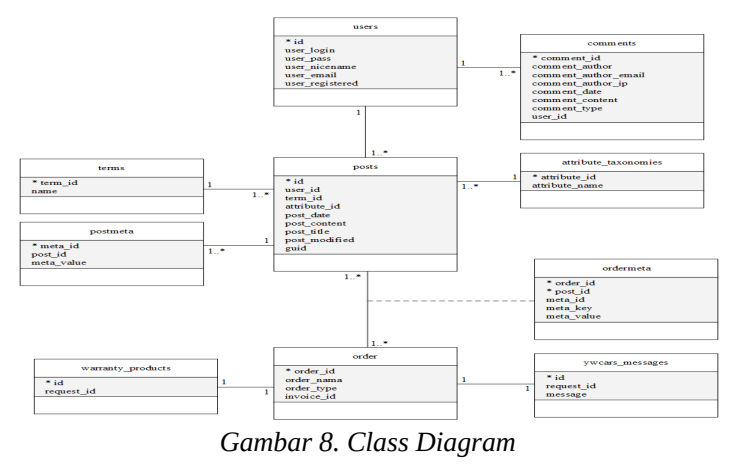

\subsection{System Sequence Diagram (SSD)}

System Sequence Diagram merupakan diagram yang digunakan untuk mengurutkan interaksi antara aktor dengan sistem[8]. Berikut adalah system sequence diagram yang dibuat oleh penulis dalam karya ilmiah ini:

a. System Sequence Diagram Pemesanan

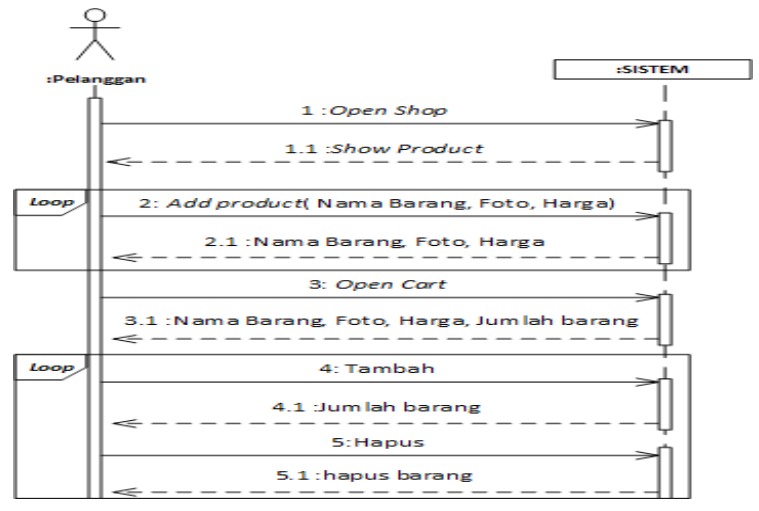

Gambar 9. System Sequence Diagram Pemesanan

b. System Sequence Diagram Konfirmasi Pembayaran

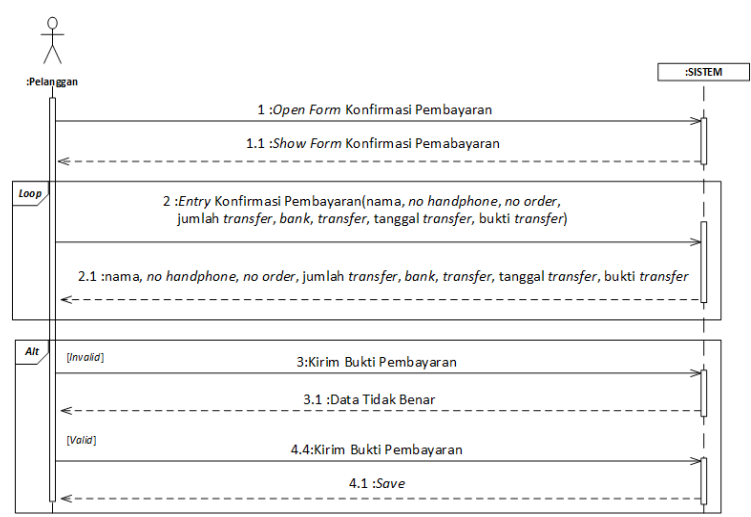

Gambar 10. System Sequence Diagram Konfirmasi Pembayaran

c. System Sequence Diagram Laporan Produk Terlaris

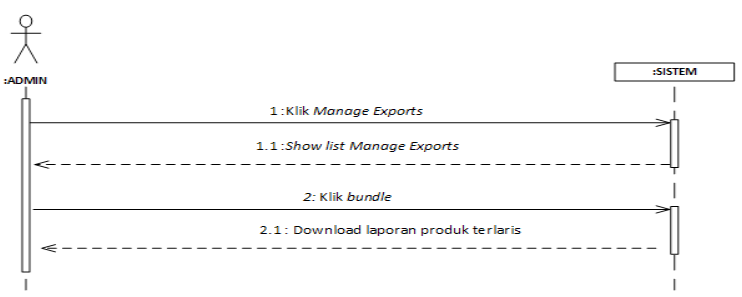

Gambar 11. System Sequence Diagram Laporan Produk Terlaris
d. System
Sequence
Diagram
Laporan 


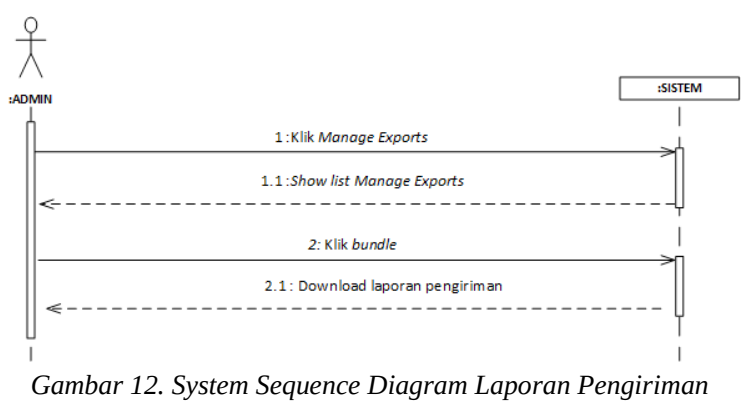

e. System Sequence Diagram Laporan Penjualan

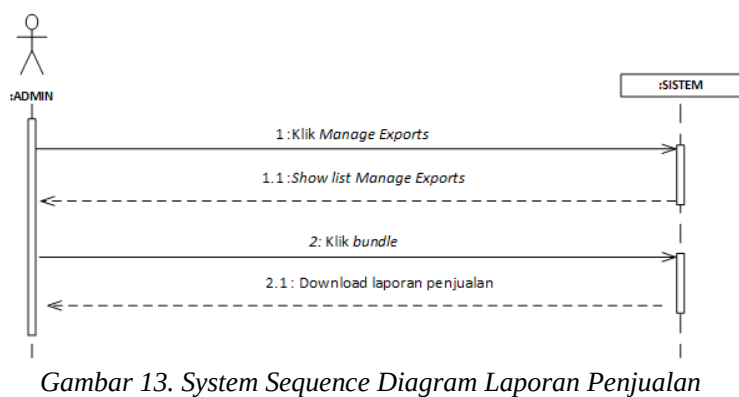

f. System Sequence Diagram Laporan Pengembalian Dana

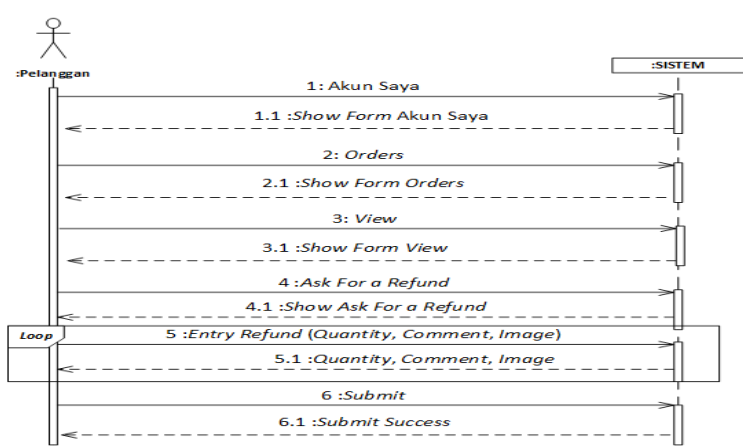

Gambar 14. System Sequence Diagram Laporan Pengembalian Dana

g. System Sequence Diagram Laporan Retur

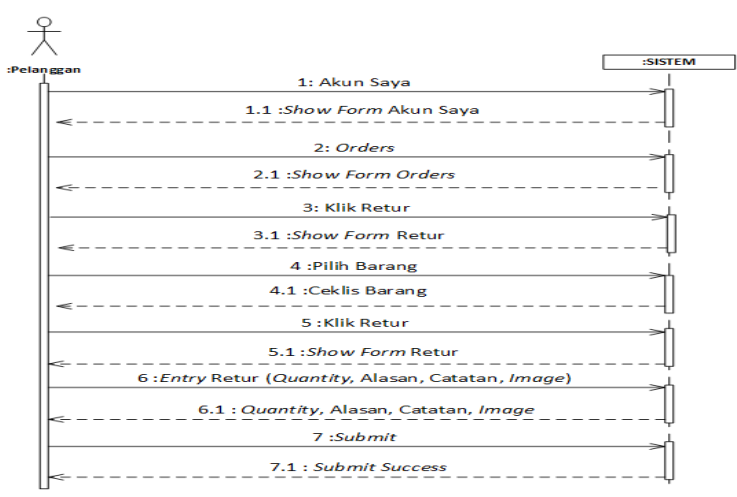

Gambar 15. System Sequence Diagram Laporan Retur

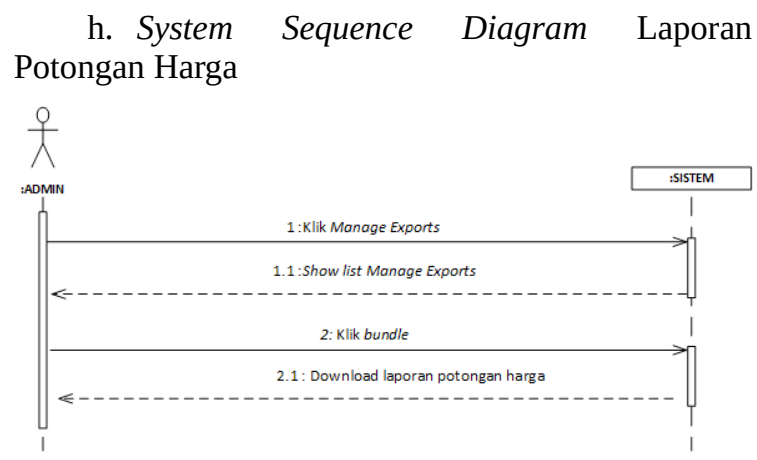

Gambar 16. System Sequence Diagram Laporan Potongan Harga

i. System Sequence Diagram Laporan Rekapitulasi

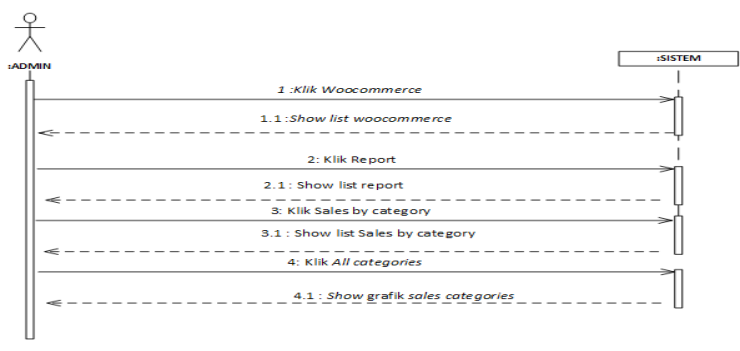

Gambar 17. System Sequence Diagram Laporan Rekapitulasi

\subsection{Tampilan Website}

Berikut ini adalah tampilan-tampilan menu dari website Fikhri Fahrul Collection:

a. Tampilan Website Pemesanan

Berikut adalah tampilan website dimana jika pelanggan ingin melihat dan membeli sebuah produk, melalui menu Belanja yang ada dibawah ini.

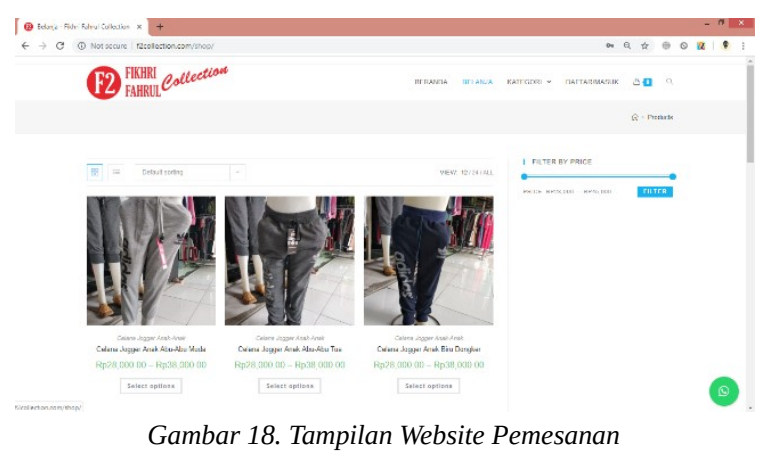

b. Tampilan Website Produk Terbaru

Berikut adalah tampilan website jika pelanggan ingin mengetahui produk-produk terbaru yang ada pada website. 


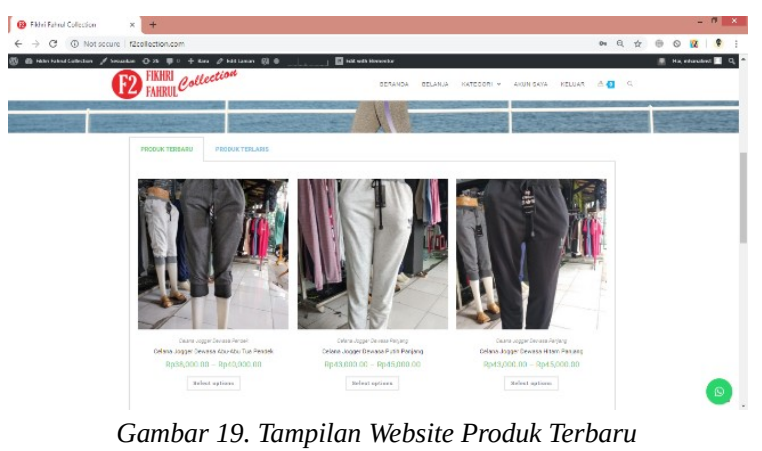

c. Tampilan Website Konfirmasi Pembayaran

Berikut adalah tampilan website jika ingin melakukan konfirmasi pembayaran produk yang sudah dipesan sebelumnya, agar pemesanan diproses lebih lanjut oleh admin.

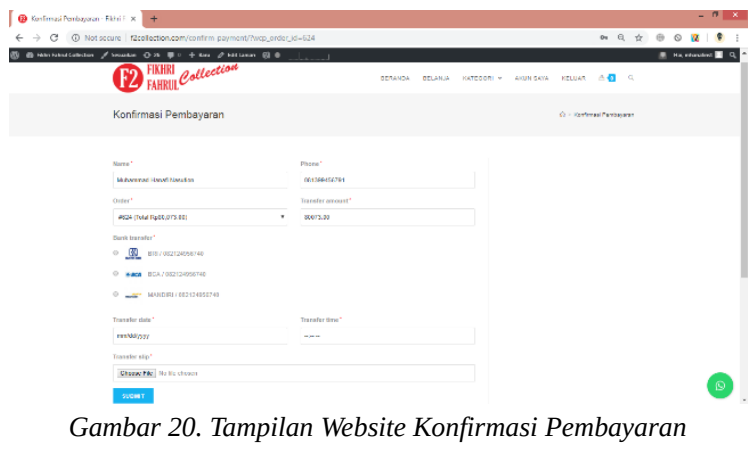

d. Tampilan Website Cetak Laporan

Berikut adalah tampilan dashboard wp-admin yang digunakan admin untuk mencetak laporanlaporan yang diperlukan.

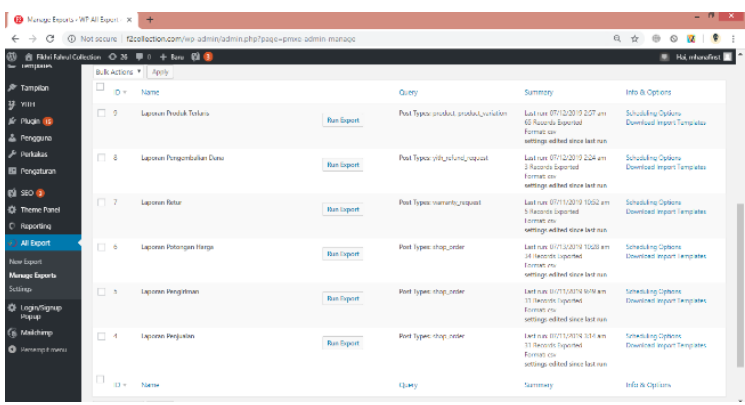

Gambar 21. Tampilan Website Cetak Laporan

\subsection{Hasil SEO}

Search Engine Optimization atau biasa juga disebut SEO adalah sebuah teknik atau cara yang digunakan agar website dapat dengan mudah dicari oleh mesin pencarian atau search engine, contohnya seperti Google[9]. Berikut adalah hasil SEO yang sudah berhasil dilakukan oleh penulis pada produkproduk di website Fikhri Fahrul Collection:

Kata Kunci: Celana Jogger Anak Biru Dongker
Kata kunci untuk produk celana jogger anak biru dongker pada website Fikhri Fahrul Collection, sudah berhasil memasuki halaman pertama pada kotak pencarian google yang diakses pada tanggal 17-06-2019.

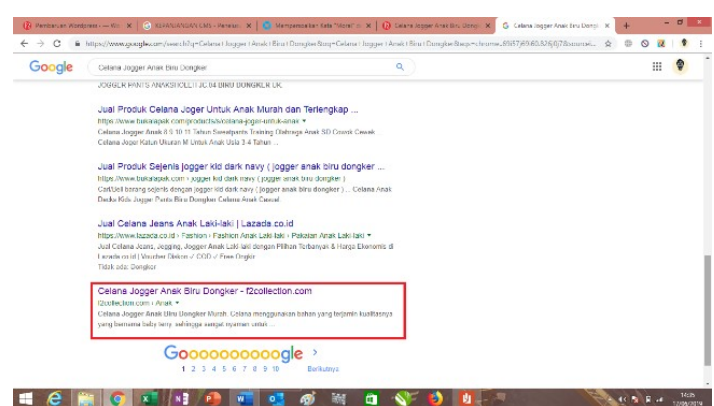

Gambar 22. Kata Kunci: Celana Jogger Anak Biru Dongker

\section{KESIMPULAN}

Dalam penulisan karya ilmiah ini, penulis dapat menarik beberapa kesimpulan diantaranya, yaitu:

a. Pelanggan tidak harus bersusah payah lagi untuk datang ke toko untuk melihat-lihat dan membeli produk, karena pelanggan cukup hanya melihat dan membelinya melalui website.

b. Pelanggan selalu mendapatkan informasi produk apa saja yang terbaru atau terupdate.

c. Kini penjual sudah bisa mengetahui beberapa laporan yang diantaranya adalah, laporan produk terlaris, laporan pengiriman, laporan penjualan, laporan pengembalian dana, laporan retur, laporan potongan harga, dan laporan rekapitulasi.

\section{DAFTAR PUSTAKA}

[1] Dewi, G., Wirdyaningsih., Barlinti, Y.S., 2018, Hukum Perikatan Islam di Indonesia, Depok, Prenada Media, p.180.

[2] Abdulloh, R., 2016, Trik Mudah Membuat CMS Website dari Nol, Jakarta, Elex Media Komputindo, p.1.

[3] Krisianto, A., 2014, Jago WordPress, Jakarta, Elex Media Komputindo, p.1.

[4] Royan, F.M., 2014, Bisnis Model Kanvas Distributor, Jakarta, Gramedia Pustaka Utama, p.1.

[5] Mulyani, S. dkk, 2019, Sistem Informasi Akuntansi: Aplikasi Di Sektor Publik: Panduan Praktis Analisis dan Perancangan Implementasi SIA di Sektor Publik, Bandung, Unpad Press, p.54.

[6] Mulyani, S. dkk, 2019, Sistem Informasi Akuntansi: Aplikasi Di Sektor Publik: Panduan Praktis Analisis dan Perancangan Implementasi SIA di Sektor Publik, Bandung, Unpad Press, p.41. 
[7] Mulyani, S., 2017, Analisis dan Perancangan Sistem Informasi Manajemen Keuangan Daerah: Notasi Pemodelan Unified Modeling Language (UML), Bandung, Abdi Sistematika, p.101.

[8] Triandini, E., Suardika, I G., 2012, Step by Step Desain Proyek Menggunakan UML, Yogyakarta, Andi Offset, p.71.

[9] Rahman, S., 2018, Buku Sakti SEO WordPress dan Joomla, Jakarta, Elex Media Komputindo, p.7. 